\title{
Experimental study on the performance of sand control screens for gas wells
}

\author{
Yan Jin · Junhai Chen $\cdot$ Mian Chen $\cdot$ \\ Fuxiang Zhang $\cdot$ Yunhu Lu $\cdot$ Jihui Ding
}

Received: 24 June 2011 / Accepted: 9 January 2012/Published online: 20 January 2012

(C) The Author(s) 2012. This article is published with open access at Springerlink.com

\begin{abstract}
Based on the sand control mechanism, similarity criterion and factors affecting the stability of borehole plastic region, a large-scale laboratory test apparatus for simulating the performance of sand control screens for gas wells was developed. A series of sand control simulation experiments were performed. Based on the particle size analysis of formation sand and geological conditions, parameters of sand control screen, such as sand retention efficiency, were investigated. By simulating formation conditions, such as pressure gradient and gas flow rate, the performance of several types of screens, including slotted screen, wire wrapped screen and premium composite screen that are commonly used in oilfield, was evaluated. Experimental results were discussed and premium composite screen was found to be most efficient for sand control among all the tested screens. This study provides a sound experimental method for evaluating the performance of sand control screens for gas wells.
\end{abstract}

Keywords Gas well $\cdot$ Sand control simulation experiment $\cdot$ Sand control screen

\footnotetext{
Y. Jin · J. Chen · M. Chen · Y. Lu · J. Ding $(\bowtie)$

State Key Laboratory of Petroleum Resources and Prospecting, China University of Petroleum, Beijing 102249, China

e-mail: jihuiding@gmail.com

F. Zhang

Tarim Oilfield Company, Xinjiang 841000, China

J. Chen

Sinopec Research Institute of Petroleum Engineering,

Beijing 100101, China
}

\section{Introduction}

Sand production can pose serious problems to normal field production. Hence, numerous methods have been proposed to perform effective sand control. Laboratory sand control simulation experiment has been considered as a good way to select appropriate sand control screens. Schulien et al. (1997) designed and constructed a small-scale laboratory test apparatus for investigating screen plugging. With this test apparatus, the influence of scale sensitive parameters on the performance of a single wire wrapped screen was studied. Ballard et al. (1999) developed a laboratory method to evaluate the performance of various sand control screens, which was applied in a North Sea oilfield to select the most appropriate screen. Underdown et al. (1999) evaluated sand control efficiency for different screens and defined performance factor and sand control factor. The higher the sand control factor, the better the sand control performance of a screen. For the performance factor, the higher the value, the longer the screen occurs sand plugging. Zhu et al. (2000) conducted laboratory sand control simulation experiments for heavy oil reservoir of Shengli oilfield, China. They investigated the adaptability of different sand control methods in different geological conditions and established an optimal sand control screen selection model. Zeng et al. (2004) designed a sand control simulation apparatus and conducted simulation experiments for shallow loose heavy oil reservoir in the Bohai Sea, China. They came to conclusion that the studied reservoir is not suitable for gravel packing, while using metal cotton fiber for sand control is more preferable. Qi (2004) designed a large-scale experimental apparatus for simulating sanding during radial flow. The relationship between fluid viscosity, flow rate and sanding was obtained. Nouri et al. (2005) used field sand to make poorly cemented 


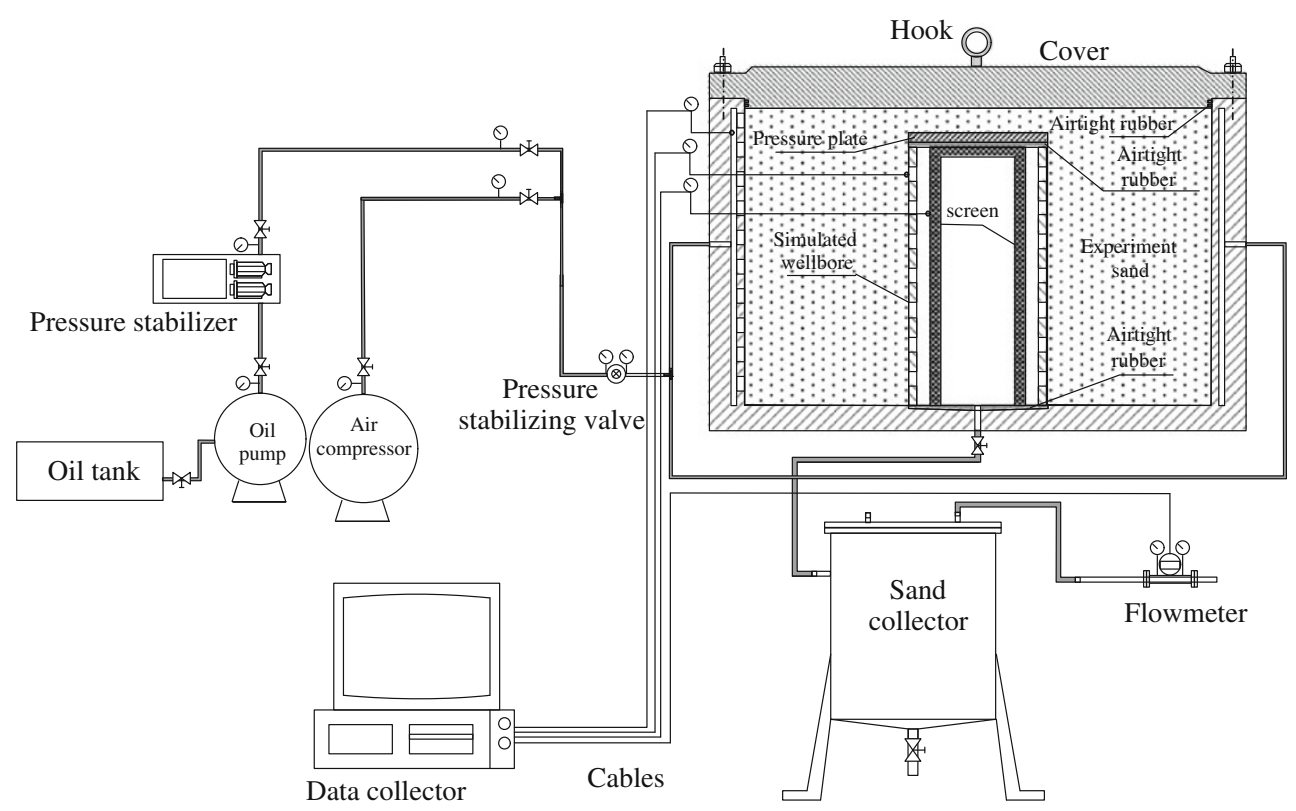

Fig. 1 Schematic diagram of sand control simulation experimental apparatus

Fig. 2 Profile of experimental cylinder and test positions

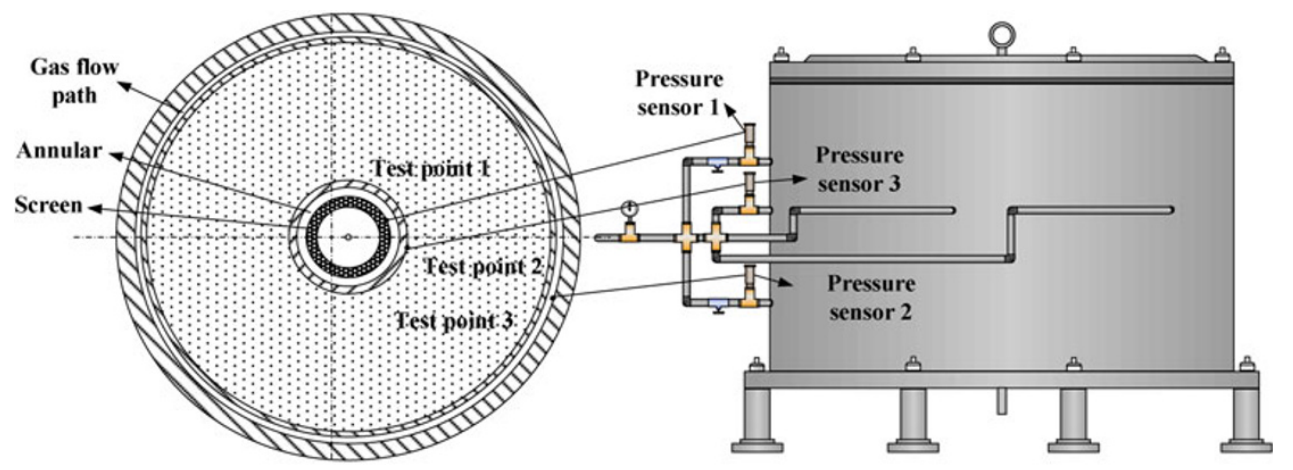

Test point 1: sand control screen entrance pressure

Test point 2: annular entrance pressure

Test point 3: sand entrance pressure

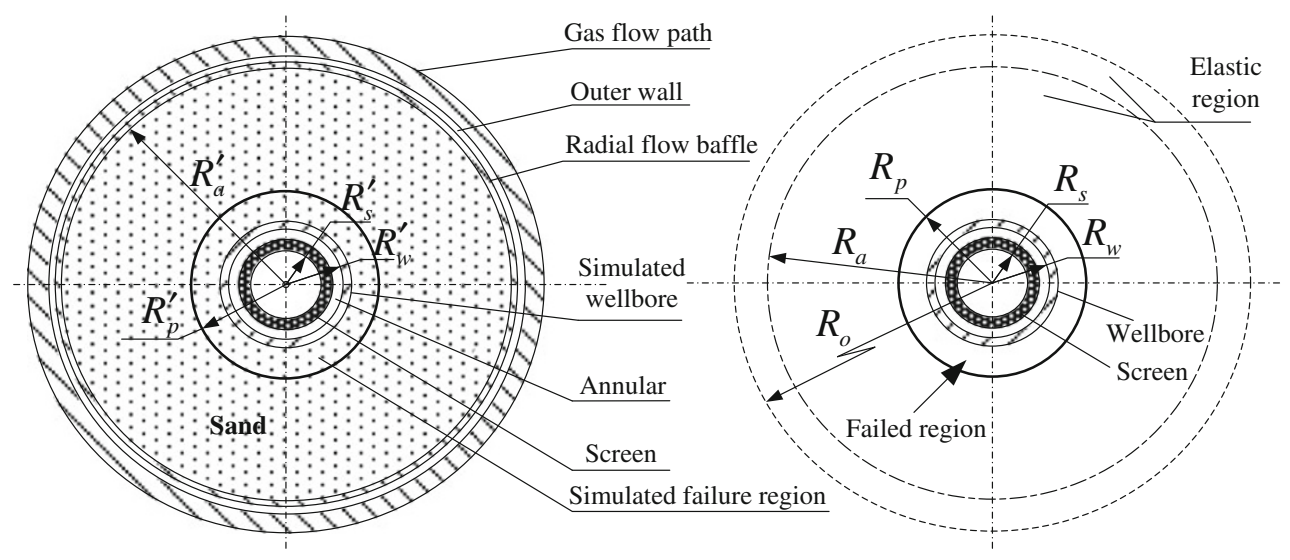

Fig. 3 Structure of experimental cylinder and dimensions of sand-filling model and field formation 
thick-walled cylinder samples. Laboratory sanding simulation experiments were conducted for both open hole completion and sand control screen completion. Sand control performance of expandable screen was analyzed as well. The experimental equipments include fluid injection system, axial loading system and sand collection system.

Numerous studies on laboratory simulation of the performance of sand control screens used in poorly consolidated reservoirs have been reported. The fluids used in the experimental simulation are most often refined oil and water. Our study focuses on the evaluation of the performance of sand control screen for gas wells. With a largescale laboratory test apparatus designed by ourselves, it is aimed to provide a sound experimental method.

\section{Experimental apparatus for sand control simulation of gas wells}

The experimental study in this paper simulates sand production for gas wells, aiming to evaluate the

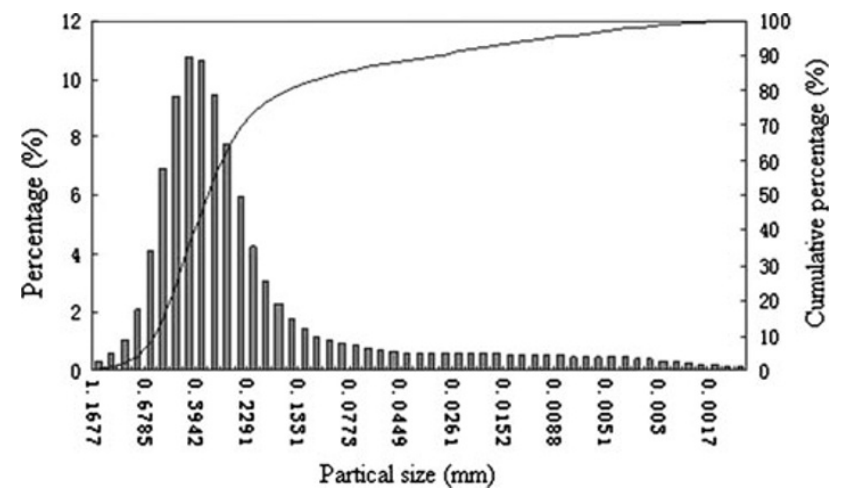

Fig. 4 Analysis of core particle sizes for Well Dabei 3 (well depth 7,066-7,067 m) performance of various sand control screens. The experimental study does not involve mechanical failure analysis of wellbore. Instead, this paper focuses on the study of when and on what conditions sand production occurs and the evaluation of the performance of several sand control screens.

The experimental apparatus consists of power system, pressure measurement system, flow rate measurement system, data acquisition system, experimental cylinder, sand collection system, simulated wellbore and auxiliary equipments, as is illustrated in Figs. 1 and 2.

\section{Determination of experimental conditions of sand control simulation for gas wells}

Simulating field conditions by conducting laboratory experiment require geometric similarity (composition of experimental and formation sand; diameter, slot height, slot length of experimental and field screen), physical similarity (production pressure difference and gas flow rate), boundary similarity. In order to establish the relationship between the performance of sand control screen, production pressure difference and flow rate utilizing experimental results, experimental conditions are determined through similarity criterion.

In this paper, letters without superscript "'” represent field parameters, whereas letters with superscript “" represent laboratory parameters. For convenience of derivation, corresponding diagram of laboratory sand-filling model and field formation is shown in Fig. 3.

\section{Composition of experimental sand}

Field core samples were collected and their particle sizes were analyzed (Fig. 4), then experimental sand was prepared accordingly (Fig. 5; Table 1).
Fig. 5 Comparison of particle sizes between experimental and formation sand

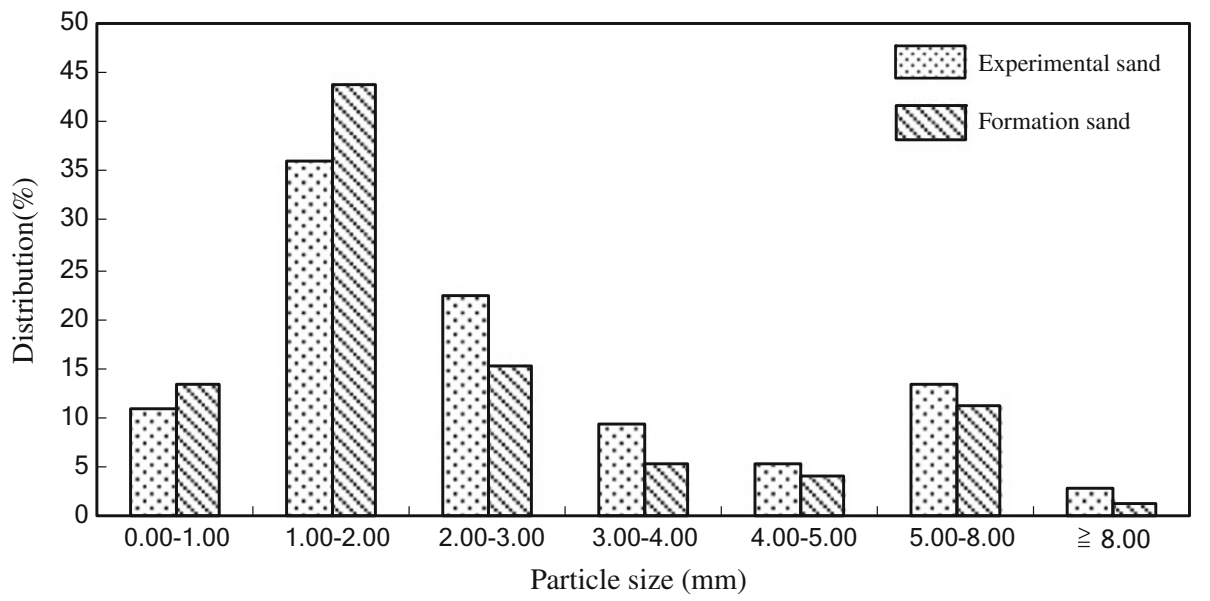

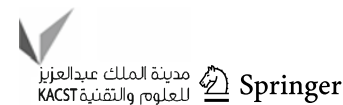


Determination of experimental pressure difference and gas flow rate

Driven by pressure gradient, formation fluid flows towards wellbore. The pressure gradient is related to formation

Table 1 Composition of experimental sand

\begin{tabular}{|c|c|c|c|c|}
\hline \multirow[t]{2}{*}{ Well no. } & \multirow{2}{*}{ Interval (m) } & \multicolumn{3}{|c|}{ Ratio of experimental sand } \\
\hline & & $\begin{array}{l}20-40 \\
\text { mesh }\end{array}$ & $\begin{array}{l}80-120 \\
\text { mesh }\end{array}$ & $\begin{array}{l}150 \\
\text { mesh }\end{array}$ \\
\hline Well Dabei 3 & $7,058-7,090.87$ & 2 & 2 & 1 \\
\hline
\end{tabular}

permeability, fluid viscosity, reservoir thickness, flow rate and model outer/inner radius. For convenience, assumptions are made as: (1) reservoir physical parameters do not change due to the small deformation of reservoir, (2) fluid viscosity is constant, (3) fluid pressure is considered as linearly distributed.

Formation pressure at position $R_{\mathrm{a}}$ can be expressed as:

$P_{\mathrm{a}}=\left(P_{\mathrm{po}}-P_{\mathrm{w}}\right) \frac{R_{\mathrm{a}}-R_{\mathrm{w}}}{R_{\mathrm{o}}-R_{\mathrm{w}}}+P_{\mathrm{w}}=\frac{\mu Q \ln \frac{R_{\mathrm{o}}}{R_{\mathrm{w}}}}{2 \pi k h} \frac{R_{\mathrm{a}}-R_{\mathrm{w}}}{R_{\mathrm{o}}-R_{\mathrm{w}}}+P_{\mathrm{w}}$.

Corresponding pressure difference between fluid and wellbore is:

Table 2 Determination of experimental gas flow rate and pressure gradient

\begin{tabular}{llllll}
\hline Item & $\begin{array}{l}\text { Wellbore radius } \\
\left(R_{\mathrm{w}},(\mathrm{mm})\right.\end{array}$ & $\begin{array}{l}\text { Outer boundary } \\
\left(R_{\mathrm{a}}, \mathrm{mm}\right)\end{array}$ & $\begin{array}{l}\text { Effective reservoir } \\
\text { thickness }(\mathrm{mm})\end{array}$ & $\begin{array}{l}\text { Pressure gradient } \\
(\mathrm{MPa} / \mathrm{m})\end{array}$ & $\begin{array}{l}\text { Gas flow rate } \\
(\text { at wellbore, } \mathrm{m} / \mathrm{s})\end{array}$ \\
\hline Well Dabei 3 & 50.8 & 225 & 9,500 & 2.37 & 0.053 \\
Experimental conditions & 50.8 & 225 & 450 & $1.6-4$ & $0.051-1.5$ \\
\hline
\end{tabular}

Table 3 Experimental sand control screens and their parameters

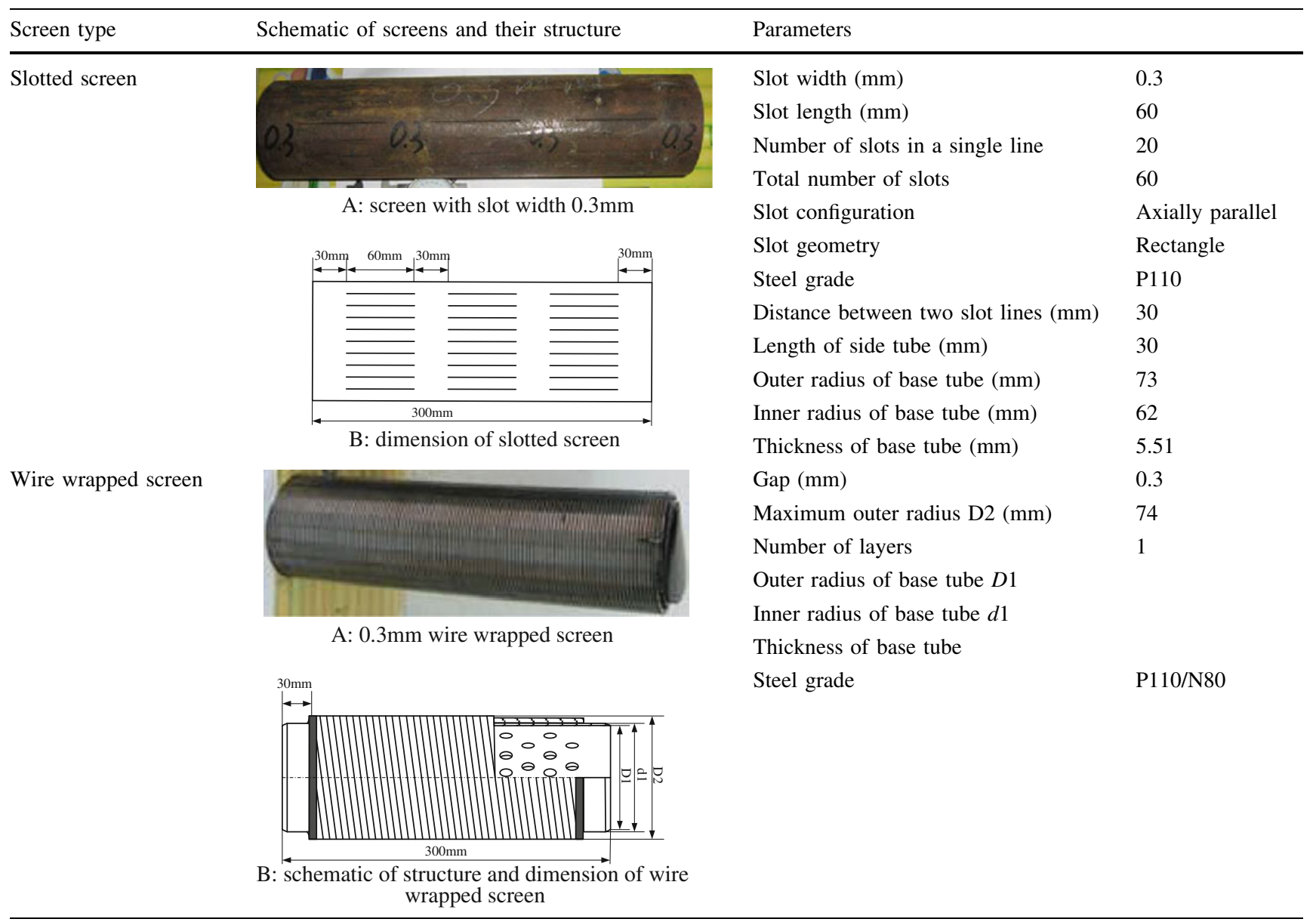


Table 3 continued

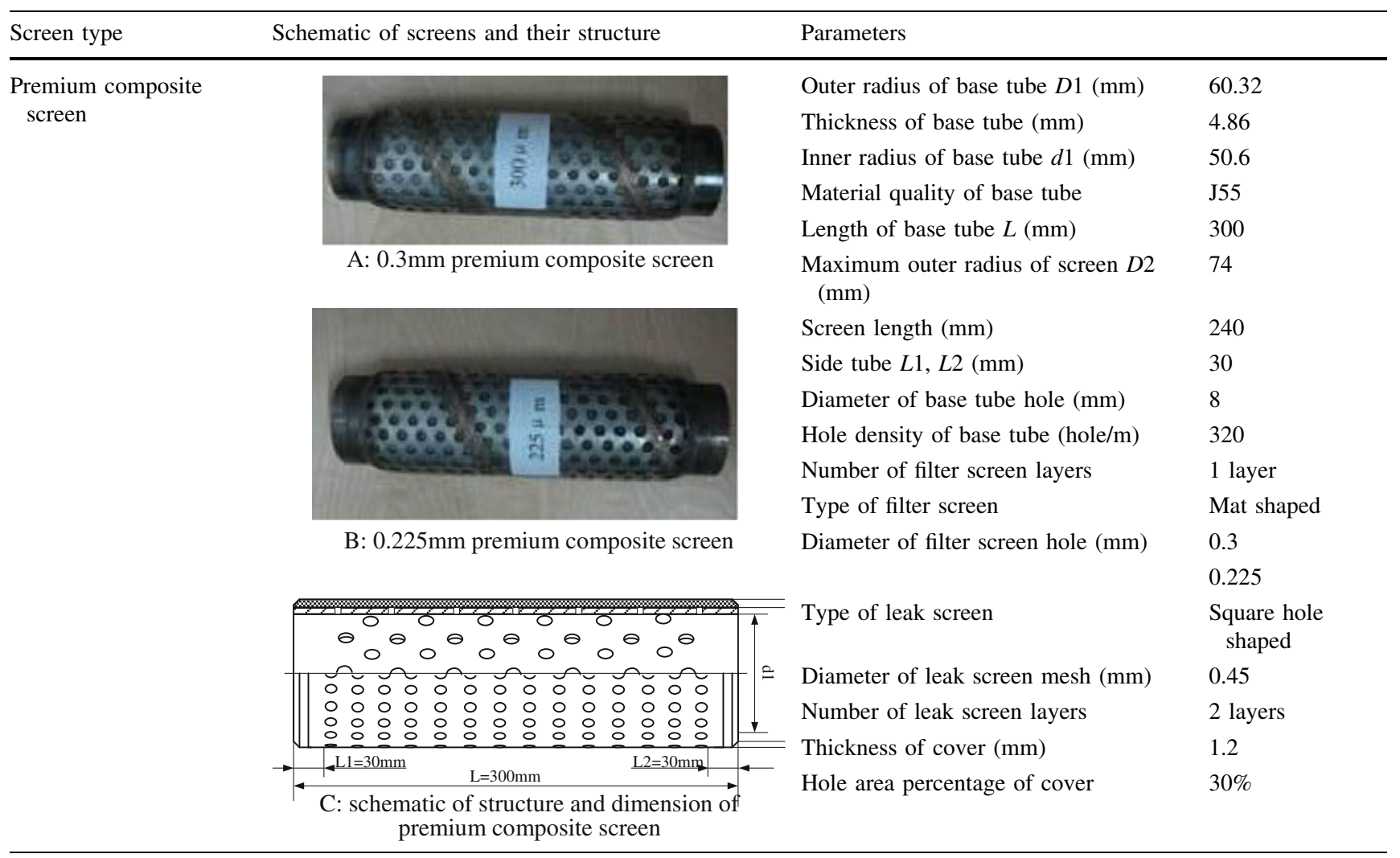

$$
\begin{aligned}
\Delta P_{\mathrm{a}} & =P_{\mathrm{a}}-P_{\mathrm{w}}=\left(P_{\mathrm{po}}-P_{\mathrm{w}}\right) \frac{R_{\mathrm{a}}-R_{\mathrm{w}}}{R_{\mathrm{o}}-R_{\mathrm{w}}} \\
& =\frac{\mu Q \ln \frac{R_{\mathrm{o}}}{R_{\mathrm{w}}}}{2 \pi k h} \frac{R_{\mathrm{a}}-R_{\mathrm{w}}}{R_{\mathrm{o}}-R_{\mathrm{w}}} .
\end{aligned}
$$

For laboratory simulation, pressure difference can be expressed as:

$\Delta P_{\mathrm{a}}^{\prime}=P_{\mathrm{a}}^{\prime}-P_{\mathrm{w}}^{\prime}=\frac{\mu^{\prime} Q^{\prime} \ln \frac{R_{\mathrm{a}}^{\prime}}{R_{\mathrm{w}}^{\prime}}}{2 \pi k^{\prime} h^{\prime}}$.

The ratio of these two pressures is:

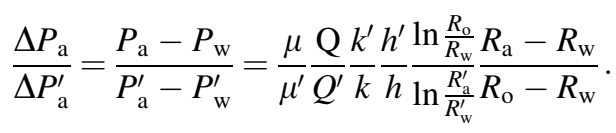

Let $\Delta P_{\mathrm{a}}^{\prime}=\Delta P_{\mathrm{a}}$, we have:

$$
P_{\mathrm{a}}^{\prime}=\left(P_{\mathrm{po}}-P_{\mathrm{w}}\right) \frac{R_{\mathrm{a}}-R_{\mathrm{w}}}{R_{\mathrm{o}}-R_{\mathrm{w}}}+P_{\mathrm{w}}^{\prime}
$$

Based on the above analysis, pressure gradients in these two conditions should be similar:

$\varpi_{\mathrm{td}}=\frac{\Delta P^{\prime} / \Delta r^{\prime}}{\Delta P / \Delta r} \approx 1$,

where pressure gradient in laboratory experiment is: $\frac{\Delta P^{\prime}}{\Delta r^{\prime}}=\frac{P_{\mathrm{a}}^{\prime}-P_{\mathrm{w}}^{\prime}}{R_{\mathrm{a}}^{\prime}-R_{\mathrm{w}}^{\prime}}$.
Gas flow rate in the field (gas passes through effective wellbore area) should be approximately similar to the gas flow rate in simulation experiment (gas passes through simulated wellbore area):

$\frac{V_{\mathrm{jb}}}{V_{\mathrm{jb}}^{\prime}}=\frac{Q / 2 \pi R_{\mathrm{w}} h}{Q^{\prime} / 2 \pi R_{\mathrm{w}}^{\prime} h^{\prime}}$,

where $V_{\mathrm{jb}}, Q, R_{\mathrm{w}}, h$ are field gas flow rate, gas production, wellbore radius and effective reservoir thickness, respectively, $V_{\mathrm{jb}}^{\prime}, Q^{\prime}, R_{\mathrm{w}}^{\prime}, h^{\prime}$ are laboratory simulated gas flow rate, gas production, wellbore radius and effective reservoir thickness, respectively.

Let $\frac{V_{\mathrm{jb}}}{V_{\mathrm{jb}}^{\prime}}=1$ and $R_{\mathrm{w}}^{\prime}=R_{\mathrm{w}}$.

Thus, $\frac{h}{h^{\prime}}=\frac{Q}{Q_{\mathrm{w}}^{\prime}}$.

It is evident that gas flow rate (at wellbore) is controlled by effective reservoir thickness and gas production (Table 2).

Table 4 Sand production for several types of screen (2.25 MPa compressor output pressure)

\begin{tabular}{ll}
\hline Screen type & Sand production $(\mathrm{g})$ \\
\hline $0.3 \mathrm{~mm}$ slotted screen & 5.363 \\
$0.3 \mathrm{~mm}$ wire wrapped screen & 0.7622 \\
$0.3 \mathrm{~mm}$ premium composite screen & 0.6315 \\
$0.225 \mathrm{~mm}$ premium composite screen & 0.2731 \\
\hline
\end{tabular}



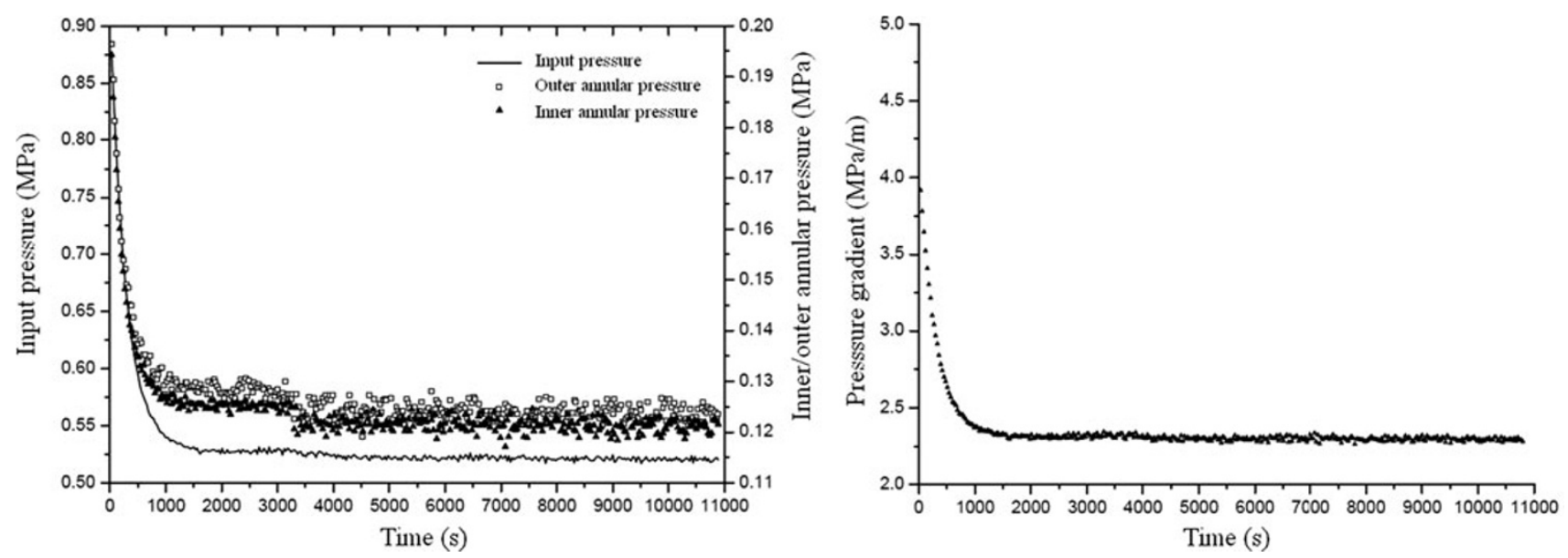

Fig. 6 Input pressure, annular pressures and pressure gradient $(0.3 \mathrm{~mm}$ premium composite screen and compressor output pressure $2.5 \mathrm{MPa})$

Fig. 7 Gas flow rate versus time and premium composite screen after experiment ( $0.3 \mathrm{~mm}$ premium composite screen and compressor output pressure $2.5 \mathrm{MPa}$ )
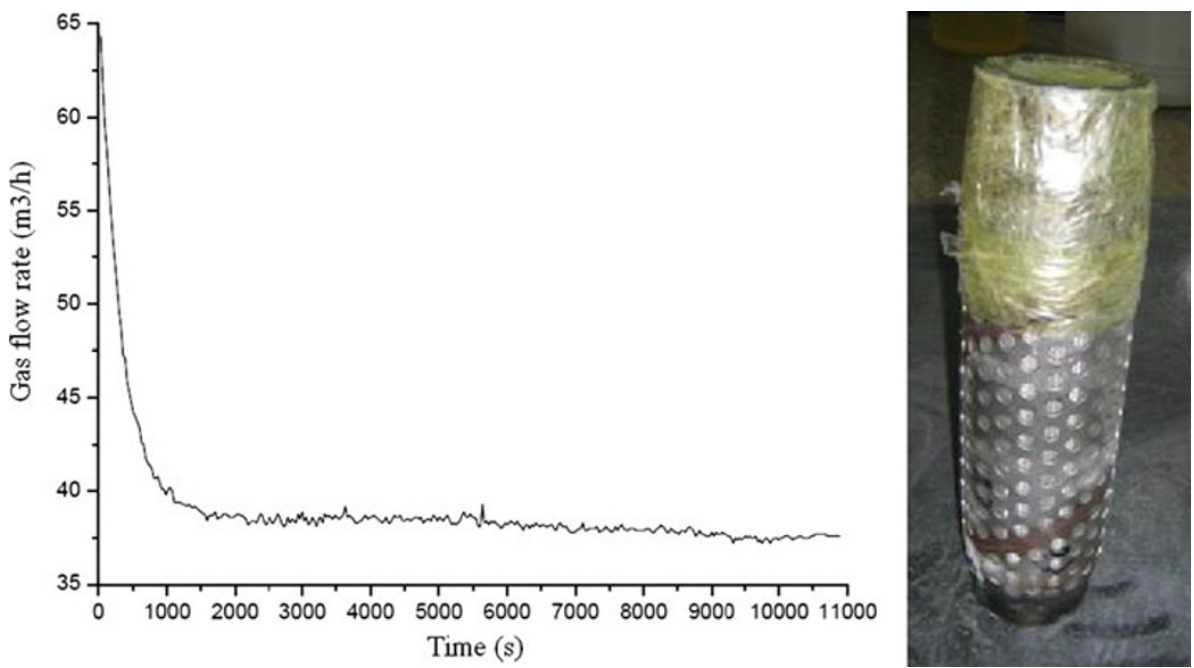
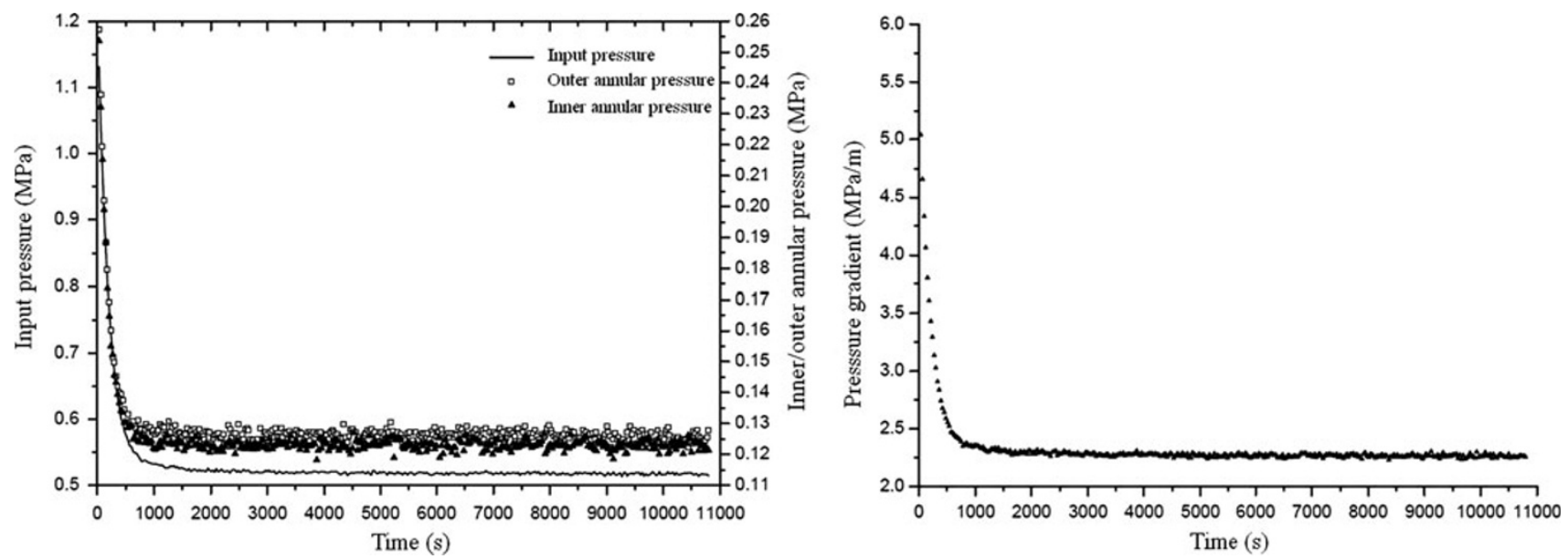

Fig. 8 Input pressure, annular pressures and pressure gradient $(0.225 \mathrm{~mm}$ premium composite screen and compressor output pressure $2.5 \mathrm{MPa})$ 


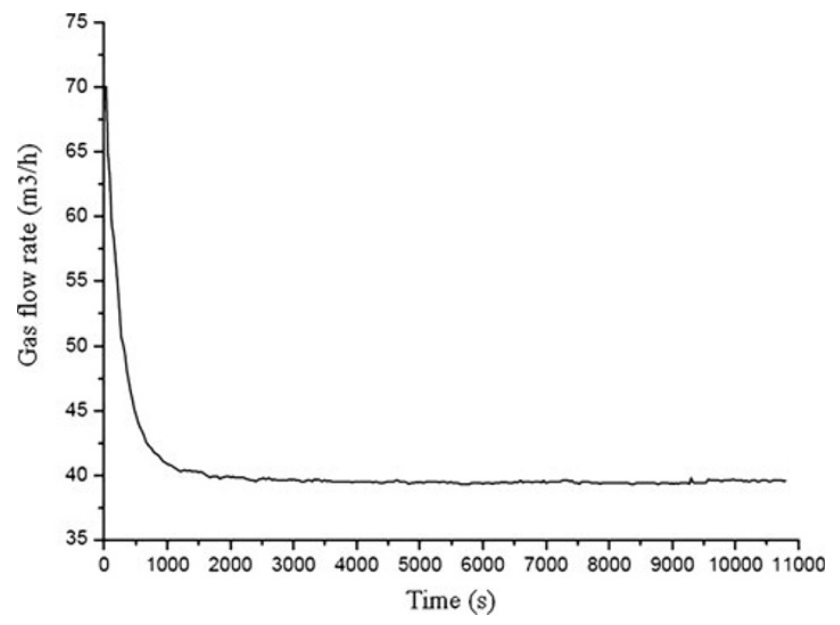

Fig. 9 Gas flow rate versus time $(0.225 \mathrm{~mm}$ premium composite screen and compressor output pressure $2.5 \mathrm{MPa}$ )

\section{Experimental results and discussion}

\section{Sand control screens and their parameters}

The most commonly used sand control screens in oilfields include slotted screen, wire wrapped screen and composite screen. Therefore, simulation experiments were conducted on these types of screens and their parameters are listed in Table 3.

\section{Experimental results}

We first conducted sand control simulation experiments to evaluate the performance of $0.3 \mathrm{~mm}$ slotted screen, $0.3 \mathrm{~mm}$ wire wrapped screen, $0.3 \mathrm{~mm}$ and $0.225 \mathrm{~mm}$ premium composite screens under $2.25 \mathrm{MPa}$ compressor output pressure. The corresponding sand production is listed in Table 4.
It is apparent that the sand control performance of premium composite screen is the best among all the tested screens. Therefore, we focus on the evaluation of two types of premium composite screens under different compressor output pressures.

1. Experimental results for 0.3 and $0.225 \mathrm{~mm}$ premium composite screens under $2.5 \mathrm{MPa}$ compressor output pressure.

Figures 6 and 7 illustrate the input pressure, inner/ outer annular pressure and gas flow rate for experiments using $0.3 \mathrm{~mm}$ premium composite screen under compressor output pressure 2.5 MPa. We can see that both input pressure and inner/outer annular pressures stay stable for a time interval of 1,500-3,500 s while the sand is stable. After $3,500 \mathrm{~s}$, three pressures decreased simultaneously, indicating partly sand instability occurs. Some sand passed through 40-mesh screen and entered into simulated wellbore while some adhered to screen. Those sand that entered into simulated wellbore was blocked by composite screen, and some would block screen and reduce both pore area and gas flow rate. As a result, the pressure difference between annular and screen increased and fine sand was more easily carried out of screen. At last, some fine sand $(0.6315 \mathrm{~g})$ passed through $0.3 \mathrm{~mm}$ premium composite screen.

Figures 8 and 9 illustrate the input pressure, inner/ outer annular pressure and gas flow rate for experiments using $0.225 \mathrm{~mm}$ premium composite screen under compressor output pressure $2.5 \mathrm{MPa}$. Three pressures stayed stable during experiment with occasional fluctuate due to partly sand instability. The pressure gradient between inside and outside cylinder kept constant at $2.26 \mathrm{MPa} / \mathrm{m}$. Moreover, gas flow rate kept stable as well, which indicates good sand control
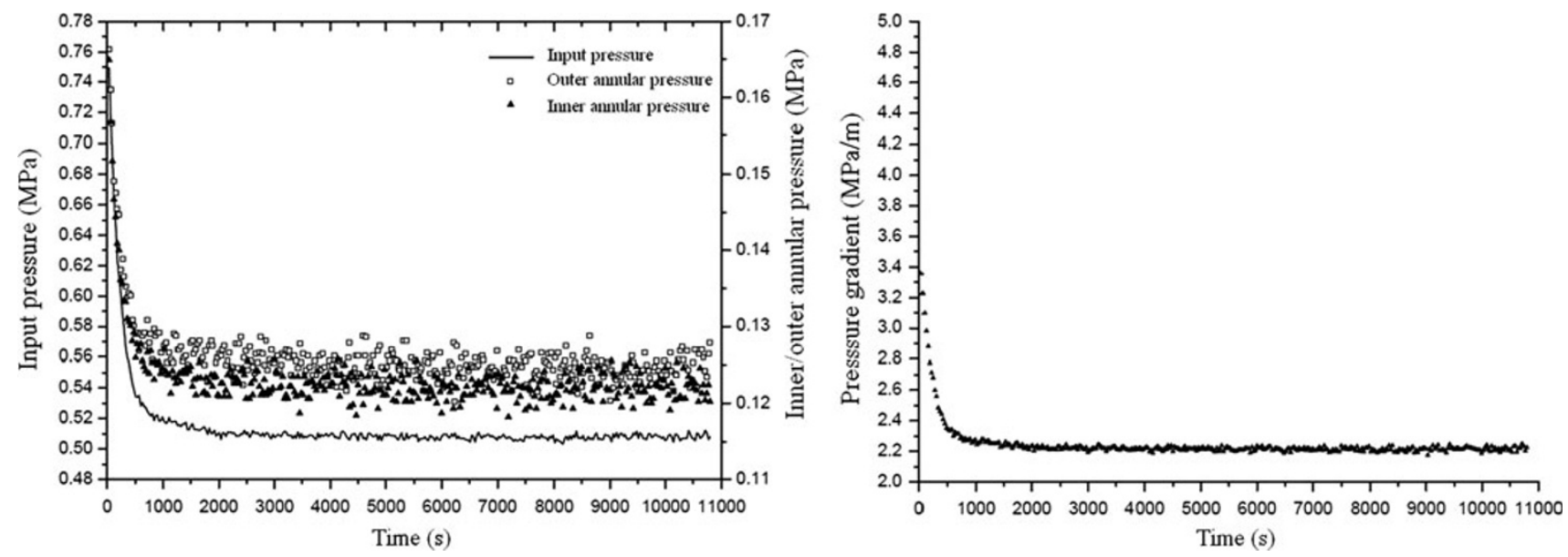

Fig. 10 Input pressure, annular pressures and pressure gradient $(0.3 \mathrm{~mm}$ premium composite screen and compressor output pressure $2.0 \mathrm{MPa})$ 


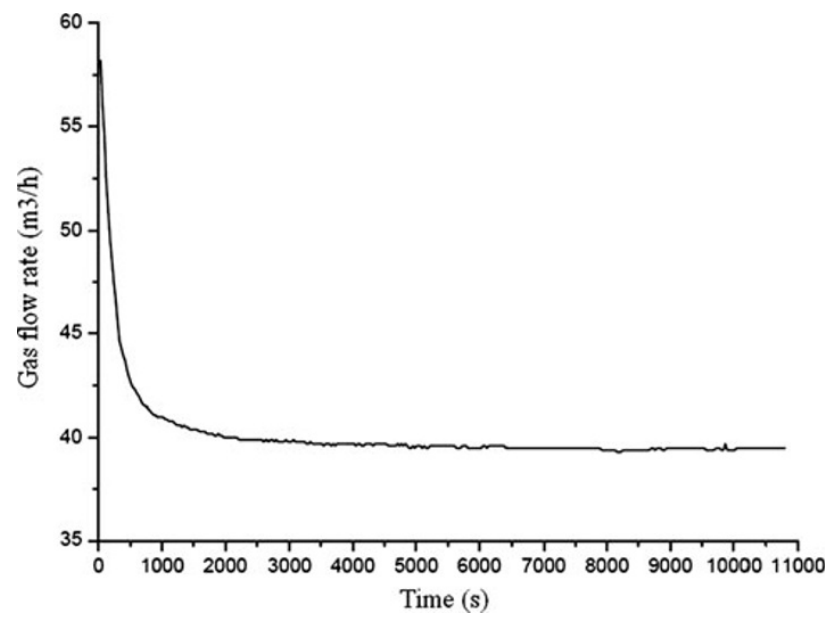

Fig. 11 Gas flow rate versus time $(0.3 \mathrm{~mm}$ premium composite screen and compressor output pressure $2.0 \mathrm{MPa}$ )

performance. At last, very fine sand $(0.2731 \mathrm{~g})$ was collected.

2. Experimental results for 0.3 and $0.225 \mathrm{~mm}$ premium composite screens under 2.0 MPa compressor output pressure.

The input pressure, inner/outer annular pressure and gas flow rate for experiments using $0.3 \mathrm{~mm}$ premium composite screen under compressor output pressure 2.0 MPa are illustrated in Figs. 10 and 11. It can be seen that input and annular pressures fluctuate, which indicates partly instability occurs. Because of great overlying pressure, fine sand entered into wellbore and had little impact on whole sand stability. Therefore, pressure gradient between inside an outside cylinder and gas flow rate roughly stayed stable. Fine sand $(0.2635 \mathrm{~g})$ was collected from sand collector, which also indicates sand instability occurs in such experimental conditions.

The input pressure, inner/outer annular pressure and gas flow rate for experiments using $0.225 \mathrm{~mm}$ premium composite screen under compressor output pressure 2.0 MPa are illustrated in Figs. 12 and 13. Three pressures fluctuated and input pressure decreased during experiment. After 5,000 s, inner and outer annular pressures slightly increased which indicates screen blocking by produced sand. While gas flow rate stayed stable and indicated screen blocking was not severe. This can also indicate that sand instability leads to sand production. Fine sand $(0.1516 \mathrm{~g})$ was collected at last.

3. Experimental results for 0.3 and $0.225 \mathrm{~mm}$ premium composite screens under 1.5 MPa compressor output pressure.

Figures 14 and 15 are for $0.3 \mathrm{~mm}$ premium composite screen under compressor output pressure 1.5 MPa. We can see that three pressures roughly stayed stable and both pressure gradient (approximately $2.25 \mathrm{MPa} /$ $\mathrm{m})$ and flow rate were constant. Probably partly sand instability occurred but sand production failed to occur. There was not any produced sand in the sand collector. Moreover, screen was found to be clean after experiment, and there was very few sand between screen and wellbore. Above phenomenon indicates sand was stable in such experimental conditions.

Figures 16 and 17 are for $0.225 \mathrm{~mm}$ premium composite screen under compressor output pressure 1.5 MPa. Sand stayed stable and three pressures kept roughly stable as well, indicating no blocking in the experiment. The pressure gradient $(1.81 \mathrm{MPa} / \mathrm{m})$ in this experiment was slightly smaller than that of
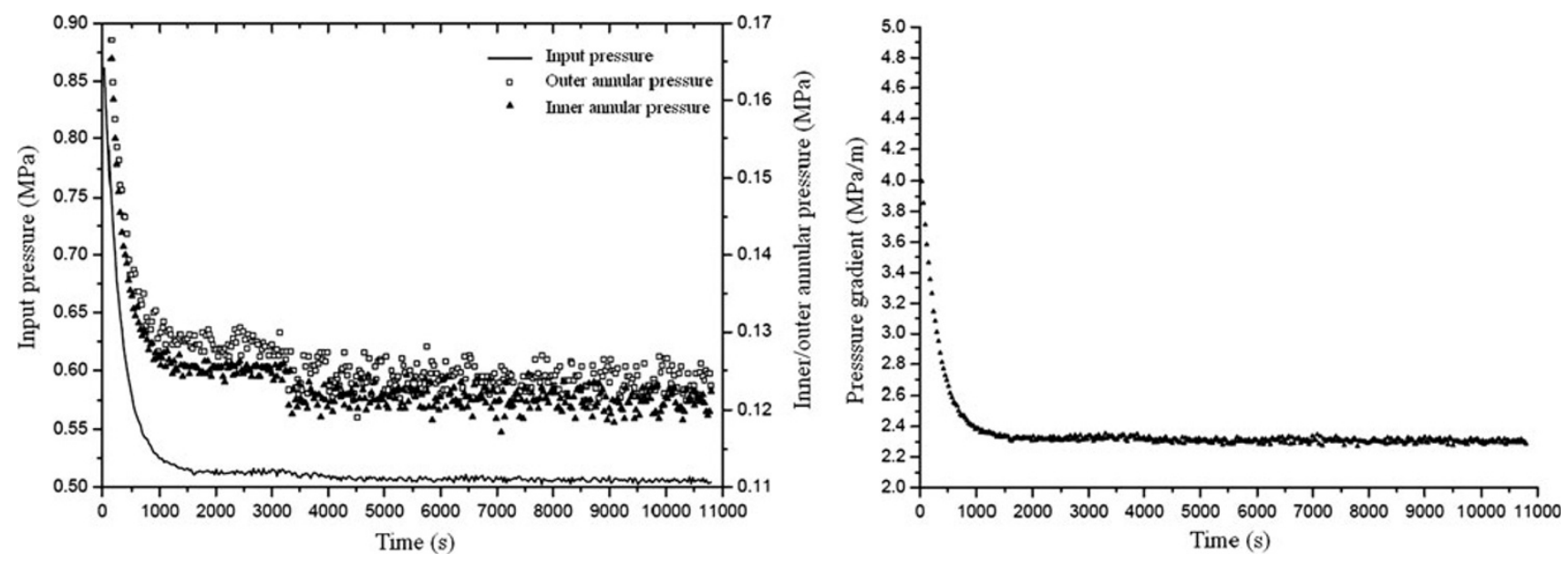

Fig. 12 Input pressure, annular pressures and pressure gradient ( $0.225 \mathrm{~mm}$ premium composite screen and compressor output pressure $2.0 \mathrm{MPa})$ 


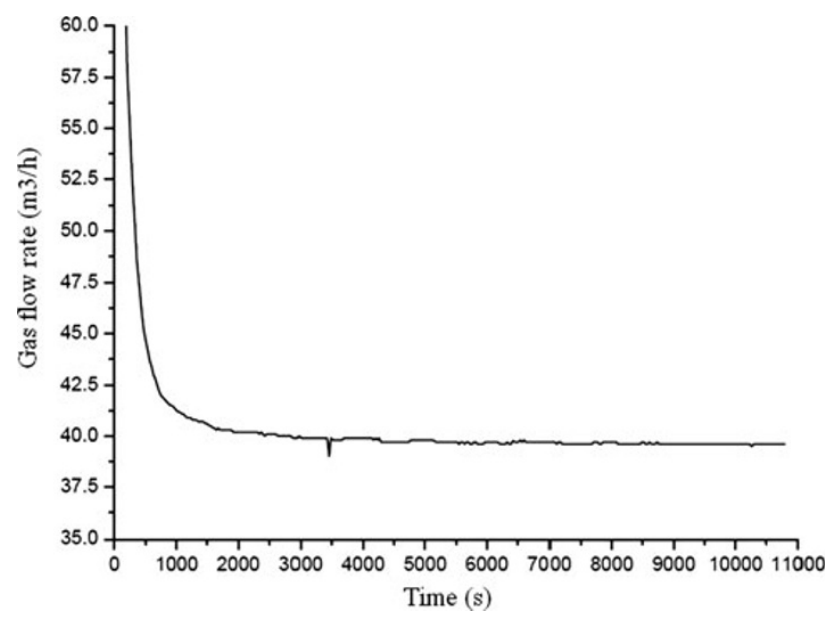

Fig. 13 Gas flow rate versus time $(0.225 \mathrm{~mm}$ premium composite screen and compressor output pressure $2.0 \mathrm{MPa})$

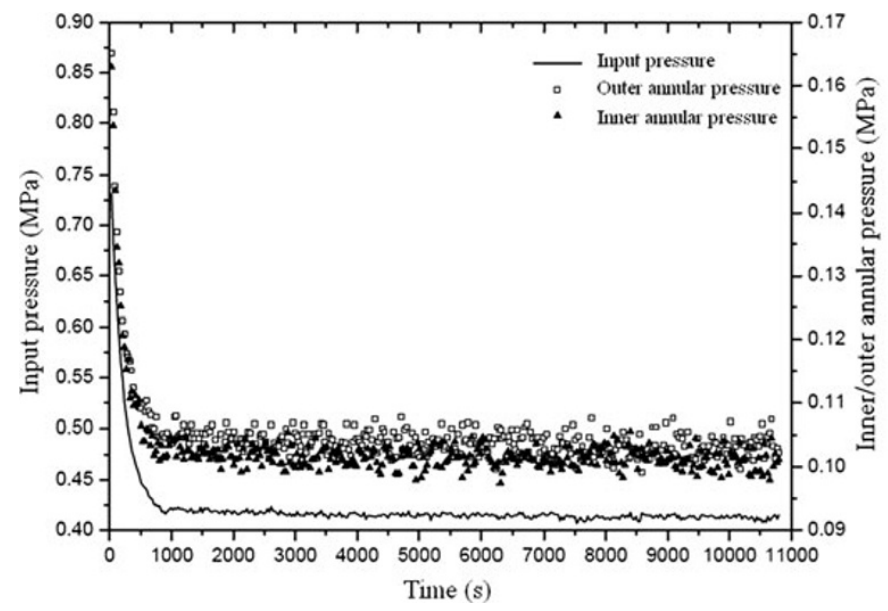

$0.3 \mathrm{~mm}$ premium composite screen. This also indicates that gas flow rate increases with open area but would result in greater pressure difference.

\section{Discussion}

Based on the above analysis of experimental results, conclusions can be drawn as follows.

For compressor output pressure $2.5 \mathrm{MPa}$, the pressure gradient between inside and outside sand-filling cylinder was $2.26 \mathrm{MPa} / \mathrm{m}$ and gas flow rate was $40 \mathrm{~m}^{3} / \mathrm{min}$, and sand instability occurred.

For compressor output pressure 2.0 $\mathrm{MPa}$, pressure gradient decreased and gas flow rate was equal to that of output pressure $2.5 \mathrm{MPa}$, partly sand instability and sand production occurred in cylinder, but the amount of

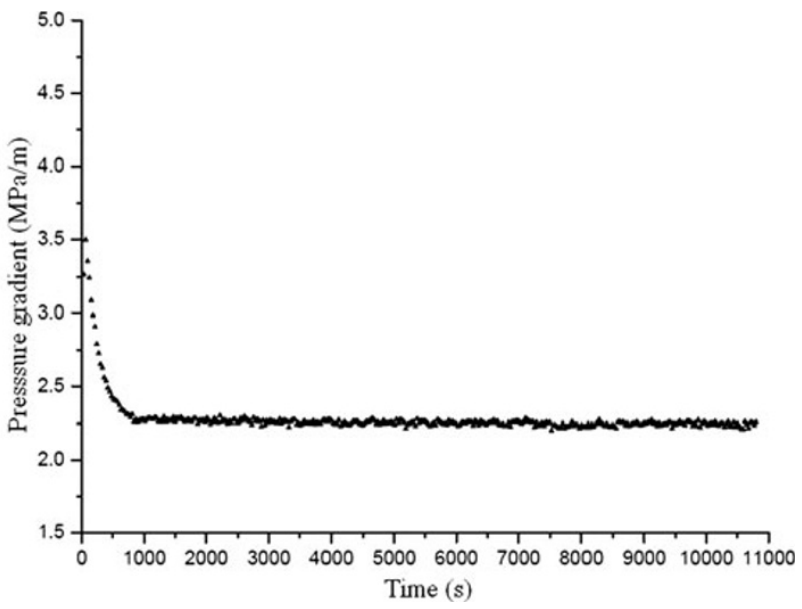

Fig. 14 Input pressure, annular pressures and pressure gradient $(0.3 \mathrm{~mm}$ premium composite screen and compressor output pressure $1.5 \mathrm{MPa})$

Fig. 15 Gas flow rate versus time and premium composite screen after experiment (0.3 $\mathrm{mm}$ premium composite screen and compressor output pressure 1.5 $\mathrm{MPa}$ )
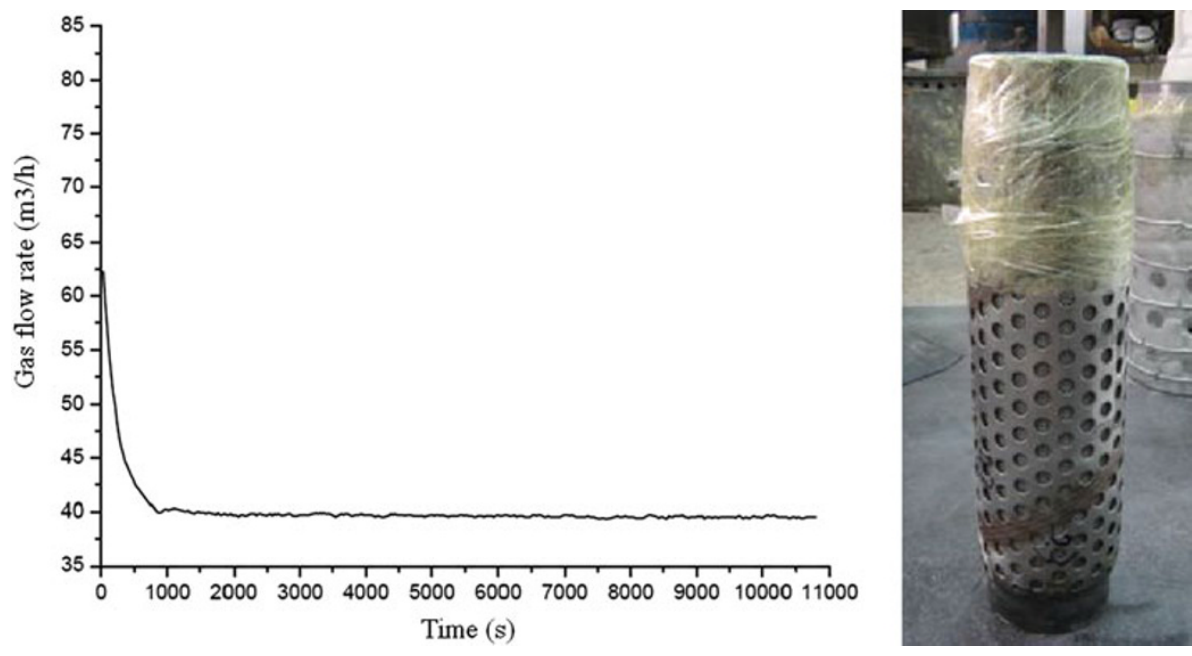

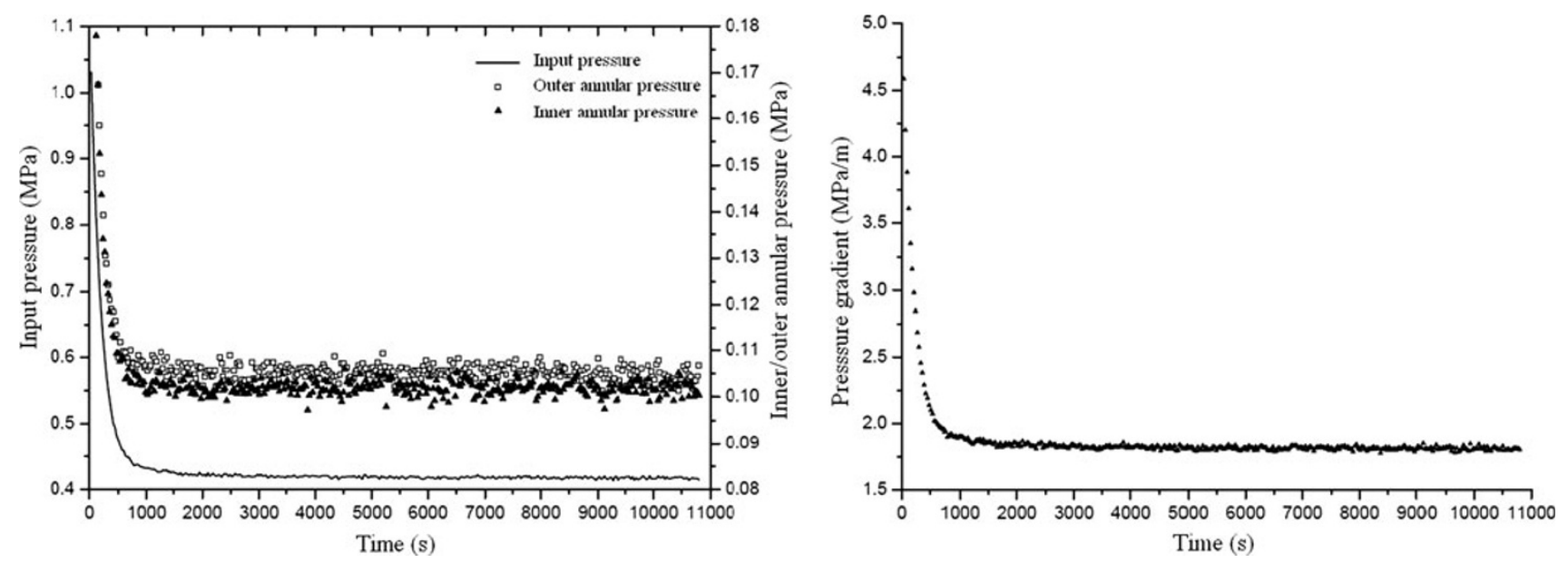

Fig. 16 Input pressure, annular pressures and pressure gradient $(0.225 \mathrm{~mm}$ premium composite screen and compressor output pressure $1.5 \mathrm{MPa})$

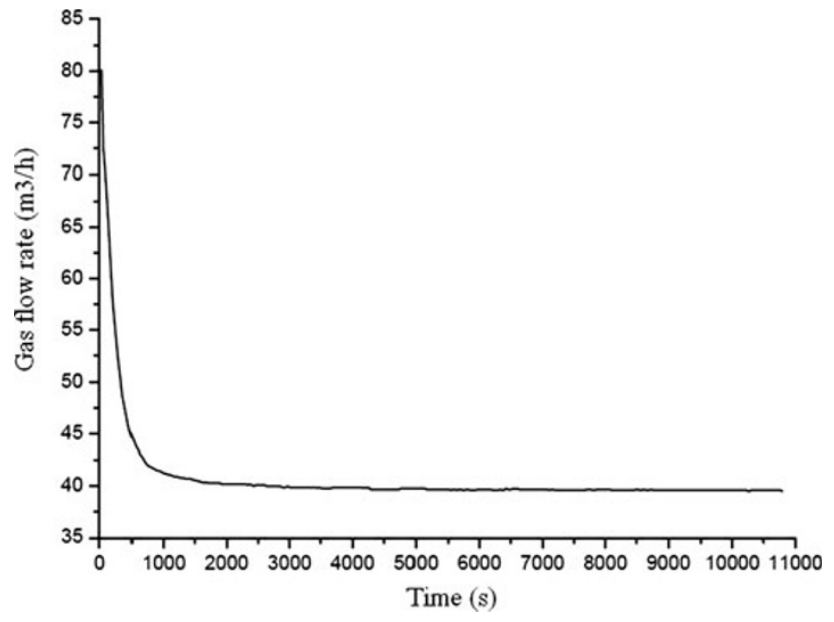

Fig. 17 Gas flow rate versus time and premium $(0.225 \mathrm{~mm}$ premium composite screen and compressor output pressure $1.5 \mathrm{MPa}$ )

produced sand was significantly less than that of output pressure 2.5 $\mathrm{MPa}$.

For compressor output pressure $1.5 \mathrm{MPa}$, pressure gradient fell between $1.81 \mathrm{snf} 2.25 \mathrm{MPa} / \mathrm{m}$ and gas flow rate was same with two former experiments, sand production failed to occur, which indicates sand is stable.

Under same conditions, sand control performance of premium composite screen is the best while slotted screen the worst.

Based on the above analysis, we know that the greater the pressure difference between inside and outside cylinder, the more instable the sand. With field pressure gradient, sand production was severe, which is consistent with field condition. By reducing pressure difference, sand tends to be stable. Therefore, once reasonable production pressure difference is adopted, wellbore plastic region can be maintained and sand production would be avoided.

\section{Summary}

A large-scale experimental apparatus for evaluating the performance of various sand control screens was developed and a series of experimental conditions can be satisfied. In the experiment, failed formation was simulated by sandfilling cylinder according to formation particle size distribution. Gas radial flow and wellbore can be simulated. Through real time measurement of input pressure, inner/ outer wellbore pressure and gas flow rate, the effect of pressure and flow rate changes on sand stability was analyzed.

Sand control simulation experimental apparatus for gas wells still needs to be further improved, especially the stability of power system, since experiment for various similarity conditions needs to be conducted accurately. Moreover, it is also advisable to develop real time sand production monitoring system in the future.

Acknowledgments This work was supported by Program for New Century Excellent Talents in University (MOE, China) and by Talim Oilfield Company of CNPC.

Open Access This article is distributed under the terms of the Creative Commons Attribution License which permits any use, distribution and reproduction in any medium, provided the original author(s) and source are credited.

\section{References}

Ballard T et al (1999) The development and application of a method for the evaluation of sand screens. SPE54745

Nouri A, Vaziri H et al (2005) A laboratory study of the effect of installation of reticulated expandable liners on sand production in weekly consolidated sandstone formation. SPE96151

Qi G (2004) Study on sand control mechanism and application of coated sand [D]. Southwest Petroleum University, Chengdu 
Schulien S, Øvsthus J et al (1997) Scale formation and treatment in and around sand control screens. SPE37305

Underdown DR, Dickerson RC et al (1999) The nominal sand control screen: a critical evaluation of screen performance. SPE56591

Zeng X, Sun F et al (2004) An experimental simulation study on sand production tendency under simple sand-exclusion conditions for the heavy oil reservoirs in Bohai sea [J]. China Offshore Oil 16(6):395-399

Zhu C, Sun H et al (2000) Optimized experimental study on sand packing methods in coarse sandstone heavy oil reservoir [J]. Spec Oil Gas Reserv 7(3):36-38 